\title{
Tomato Seed-Associated Bacteria Confer Protection of Seedlings Against Foliar Disease Caused by Pseudomonas syringae
}

\author{
Norma M. Morella, ${ }^{1, \dagger}$ Xuening Zhang, ${ }^{2}$ and Britt Koskella, ${ }^{3, \dagger}$ \\ ${ }^{1}$ Department of Plant and Microbial Biology, University of California, Berkeley, CA 94720, U.S.A. \\ ${ }^{2}$ Department of Environmental Science Policy and Management, University of California, Berkeley, CA 94720, \\ U.S.A. \\ ${ }^{3}$ Department of Integrative Biology, University of California, Berkeley, CA 94720, U.S.A. \\ Accepted for publication 6 May 2019.
}

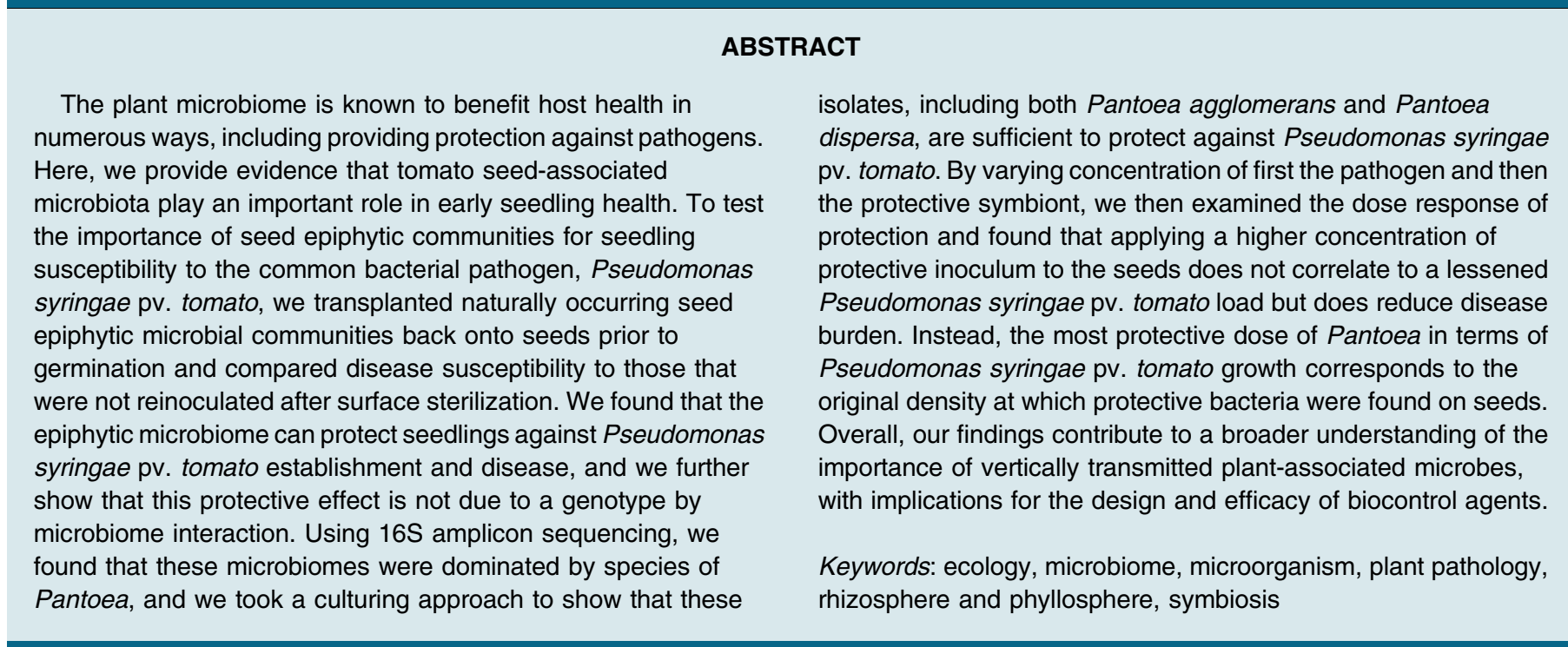

Plant associated microbiomes are capable of enhancing host fitness through a number of mechanisms. They can promote growth through production of phytohormones (Egamberdieva et al. 2017)

${ }^{\dagger}$ Corresponding authors: N. M. Morella; morella@berkeley.edu,

and B. Koskella; bkoskella@berkeley.edu

First and second authors contributed equally.

Funding: Financial support for this project was provided in part by UC Berkeley's Student Mentoring and Research Teams (SMART) program in addition to a summer fellowship provided to X. Zhang by the American Society of Plant Biologists Summer Undergraduate Research Fellowship (Zhang).

*The $\boldsymbol{e}$-Xtra logo stands for "electronic extra" and indicates that four supplementary figures and two supplementary tables are published online.

The author(s) declare no conflict of interest. The authors have a patent pending for strains relating to this work.

(C) 2019 The American Phytopathological Society and fixation of nutrients from the environment (Fürnkranz et al. 2008; Zahran 1999), confer both drought and stress tolerance (Badri et al. 2013; Lau and Lennon 2012), and even influence flowering time of their hosts (Wagner et al. 2014). Perhaps one of the most influential ways that microbial organisms affect host fitness is through their impact on host immunity and disease resistance. In plants, microbes can confer disease resistance through both indirect and direct mechanisms and can indirectly protect against disease via the plant immune system. Plants are able to detect microbialassociated molecular patterns such as lipopolysaccharides (LPS) in the environment, activating a generalized antimicrobial defense mechanism, and effectively priming the plant to respond more effectively when subsequently exposed to a pathogen (Jones and Dangl 2006; Newman et al. 2007; Zamioudis et al. 2015).

Experimental studies using isolated strains of bacteria have demonstrated that many can protect plants against pathogen colonization through direct inhibition of the pathogen's growth, either through competition for resources (Innerebner et al. 2011) or 
production of antimicrobials (Pusey et al. 2011). Furthermore, there is long-standing understanding that plants can be 'primed' against pathogen colonization by colonization of nonpathogenic bacteria (Conrath 2011). It is now becoming clear that the microbiome as a whole might act collectively to confer disease resistance, although it is more difficult to pinpoint mechanisms underlying the effects of whole consortia compared with studying individual strains using culture-dependent methods. Both the rhizosphere (Santhanam et al. 2015) and phyllosphere microbiomes (Berg and Koskella 2018; Christian et al. 2017; Ritpitakphong et al. 2016) have recently been shown to provide protection against pathogens. But even as we begin to understand microbiome-mediated protection against disease, it is unclear how a naturally protective community might assemble on a plant, and, once assembled, if it can be stably maintained over time. A broader consideration of how plant-associated microbiomes are acquired and transmitted among hosts is required to better understand how a generally beneficial community might persist across generations.

The two dominant sources for assembly of the plant microbiome are horizontal transmission from the environment and unrelated plants and vertical transmission from parental plants. Local plant populations are important contributors to the airborne microorganism community, and thus that movement of microbes among neighboring plants can readily occur through aerial dispersal (Lymperopoulou et al. 2016). Unlike horizontal transmission, however, vertical transmission holds potential to connect, extend, and reinforce beneficial symbioses across temporal and spatial scales. In plants, vertical transmission of microbial communities is observed in both vegetative (Vannier et al. 2018) and sexual reproduction (Rezki et al. 2018). Parental microbiota can be transmitted through the foliar and vascular pathways onto seeds, where they can act as the incipient members of a mature plant microbiome, critically shaping growth, development, and susceptibility to pathogens of newly emerging seedlings. Such transmission would allow plant lineages to maintain beneficial symbioses across multiple generations and pave the way for coevolution of the partners, as has been well-characterized in other systems (e.g., aphids and their vertically transmitted symbiont, Buchnera aphidocola) (Douglas 1998). Indeed, recent work investigating tomato seed endophytes suggests plants may preferentially transmit plant growth promoting bacteria to the next generation (Bergna et al. 2018).

Overall, studies of the biological significance of vertically transmitted seed microbiota remain fragmented, with a large focus on seed-mediated transmission of pathogens. High-throughput community profiling has offered important insight to seedassociated microbiomes (Shade et al. 2017) but often lacks support from experimental manipulation, limiting the scope of conclusions on their ecological implications (see Links et al. (2014) for an elegant counter-example). Moreover, studies on seedassociated microbes have focused primarily on endophytes from surface-sterilized seeds, despite the fact that the seed surface is the most immediate interface between the embryo and parental tissues. As a result, endogenous seed epiphytes remain a relatively unexplored group, despite their potential importance in early colonization of plants. Here we present a study in which we examine whether endogenous seed epiphytic microbes, both as a community and in isolation, protect seedlings of various tomato types against a common plant pathogen, Pseudomonas syringae pv. tomato strain DC3000. By transferring naturally occurring seed-associated microbial communities back onto surface-sterilized seeds of either the original cultivar or different genotypes, and comparing pathogen colonization and disease susceptibility against uninoculated control seedlings, we were able to test the impact of multiple seed- associated communities and bacterial isolates on disease progression, and examine the dose dependence of protection conferred.

\section{MATERIALS AND METHODS}

Tomato fruit and seed collection. Tomato fruits were collected from UC Davis Student Organic Farm in September 2017. We collected mature, intact fruits from a total of four different tomato types based on distinct fruit morphologies and field locations including: orange cherry tomatoes, red cherry tomatoes, mediumorange-sized tomatoes, and an unidentified heirloom variety. Fruit of the same tomato type/cultivar were collected from multiple plants planted in the same row, resulting in four tomato types (designated as Tomato Type 1-4). Tomato Type 1-3 were collected from nonneighboring lanes from one field, and the heirloom variety (Tomato Type 4 [TT4]; generated by the Student Collaborative Organic Plant breeding Education (SCOPE) program; USDA-NIFA award number 2015-51300-24157) was collected from a neighboring field. Fruits were transported to UC Berkeley on ice and immediately stored in $4{ }^{\circ} \mathrm{C}$ until processing. Intact tomato fruits from the same type were pooled in a sterile 1-liter beaker until they reached roughly the $500 \mathrm{ml}$ line (approximately 10 to 20 tomatoes). To ensure that no additional microbes other than those found naturally were introduced to the seed surface, we surface sterilized the tomato fruits themselves before processing of seeds. Tomatoes were submerged in $75 \%$ ethanol for $20 \mathrm{~min}$. They were then washed with sterile double-distilled $\mathrm{H}_{2} \mathrm{O}\left(\mathrm{ddH}_{2} \mathrm{O}\right)$ three times. The last wash was plated onto Kings Broth (KB) agar (King et al. 1954), and no colony forming units (CFUs) were detected. Sterilized tomatoes were then pooled into another sterile 1-liter bottle, crushed with sterile forceps and spatula until becoming a thick fruit mixture, and allowed to ferment at room temperature (approximately $20^{\circ} \mathrm{C}$ ) for 7 days. We employed this as a common seed collection method for removal of seeds from the fruit endocarp. After fermentation, seeds were then strained out from the fermented liquid with a sterilized metal strainer, minimally washed with sterile $\mathrm{ddH}_{2} \mathrm{O}$ to remove any excess fruit, and dried on filter paper within sterile petri dishes. All procedures were carried out sterilely in a Biological Safety Cabinet. Harvested seeds were stored in sterile petri dishes in darkness at $21^{\circ} \mathrm{C}$, and these same seed stocks were used for all experiments. The first experiment was performed less than 1 month after collection, and the last experiment was done 6 months after collection.

Germinating TT1 to TT4 seeds with/without their endogenous microbiota. For each experimental replicate within an experiment (six per treatment), six seeds from each field-collected tomato type were placed into sterile 1.5-ml Eppendorf tubes and submerged in $400 \mu \mathrm{l}$ of sterile $10 \mathrm{mM} \mathrm{MgCl}$ solution and sonicated for 15 min in a Branson M5800 sonicator. This sonicating water bath is different from laboratory sonicators used to disrupt cells; instead, these baths will dislodge bacteria with minimal disruption of their cell integrity. The liquid was then transferred into new sterile tubes and used as seed microbiome inocula. Prior to inoculation, seeds were surface sterilized using the following procedure. Seeds were first soaked in $2.7 \%$ bleach (sodium hypochlorite) solution for $20 \mathrm{~min}$, and then washed with sterile $\mathrm{ddH}_{2} \mathrm{O}$ three times to remove any excess bleach. The last washes were plated on $\mathrm{KB}$ agar plates and incubated at $28^{\circ} \mathrm{C}$ for $24 \mathrm{~h}$. No culturable bacteria were present in any poststerilization seed wash from any experiments. After sterilization, $40 \mu \mathrm{l}$ of the original seed wash (bacterial inoculum) was pipetted directly on top of each individual seed. We did this so that each seed would receive roughly the same number of microbes that was removed during the sonication step. The removal and re-addition process was done, in general, so that every seed used in the 
experiment would undergo the exact same procedure, and the only difference would be receiving microbiota or not. Negative control seeds were each inoculated with $40 \mu \mathrm{l}$ of $10 \mathrm{mM} \mathrm{MgCl}_{2}$.

Germinating TT1 and TT2 with/without TT4 microbiota. In this experiment, microbiota was removed from TT1, TT2, and TT4 seeds via surface sterilization, as described above. In this case, for every experimental replicate of TT1 and TT2 (each with six seeds), an equivalent number of TT4 seeds from our original seed stock were used to generate microbial seed inoculum. We had a total of five experimental replicates per tomato type, per treatment. After sterilization, TT1, TT2, and TT4 seeds were all inoculated with either TT4 microbiota or $40 \mu \mathrm{l}$ of $10 \mathrm{mM} \mathrm{MgCl}_{2}$. As above, $40 \mu \mathrm{l}$ of seed wash (or buffer) was pipetted directly on top of each seed within an experimental replicate.

Culturing and growth of isolates. In order to culture bacteria from the seeds used in this experiment, seeds were sonicated into sterile buffer, as above. Next, the seed wash was diluted 1:10 in sterile $10 \mathrm{mM} \mathrm{MgCl}$, solution and plated onto $\mathrm{KB}$ agar and Lysogeny broth (LB) (Bertani 1951) agar. They were incubated for $48 \mathrm{~h}$ at $28^{\circ} \mathrm{C}$. We were only able to culture bacteria from TT4 and TT2. On average, we cultured 40 CFUs ( \pm standard error 0.53 ) from each TT4 seed. To isolate individual strains from the microbial community, we picked morphologically distinct colonies, based on color and surface, and streaked them on new nutrient agar where they were grown for $24 \mathrm{~h}$ at $28^{\circ} \mathrm{C}$. Liquid cultures were attained by inoculation into liquid $\mathrm{KB}$ and grown on an orbital shaker at $28^{\circ} \mathrm{C}$ overnight.

Germinating Money Maker seeds with/without live bacterial isolates. For consistency among tomato plant hosts, Money Maker seeds were used for all further experiments measuring the impact of particular seed-associated microbiota. Seeds were sterilized as described above. In addition to testing our own bacterial isolates ZM1, ZM2, and ZM3, we also included biological control strains, provided by V. Stockwell, Oregon State. These two strains are Pantoea agglomerans strain E325A and Pantoea vagans strain C91. Bacterial inoculum was prepared as follows. Isolates were grown overnight on an orbital shaker in $\mathrm{LB}$ at $28^{\circ} \mathrm{C}$. We measured the optical density at $600 \mathrm{~nm}\left(\mathrm{OD}_{600}\right)$ of the overnight culture and plated the culture on LB agar, incubated overnight at $28^{\circ} \mathrm{C}$ to obtain their CFU counts. The remainder of the liquid culture was stored at $4^{\circ} \mathrm{C}$ overnight. The next day, we calculated a CFU to OD ratio, and remeasured the OD to account for any growth that occurred of the liquid culture overnight. We pelleted the bacteria at $4,000 \times g$ for 5 min, resuspended in sterile $10 \mathrm{mM} \mathrm{MgCl}$ solution, and diluted to the appropriate concentration. Each seed was inoculated by pipetting the bacterial culture directly on top of each individual seed. In Seeds were inoculated with pure cultures of bacterial isolates at a final inoculum density of $40 \mathrm{CFU} / \mathrm{seed}$ to approximately match the observed natural densities. Each experimental replicate held four seedlings, and we had three experimental replicates per isolate per treatment. Disease severity was monitored for 10 days after plate flooding (see below). For dose response curves the density of bacteria applied to the seeds ranged from $4 \times 10^{-1}$ to $4 \times 10^{6} \mathrm{CFU} / \mathrm{seed}$ with control replicates not receiving any, and disease was monitored for 9 days. We did not replicate at the plate level for dose response curves.

Effects of UV-killed bacterial isolates. Liquid bacterial cultures were prepared as above. In addition to Pantoea strains, we included a nonenvironmental bacterium: E. coli BW25113 (Baba et al. 2006). To UV kill bacteria, $500 \mu$ l of diluted cultures was exposed to UV radiation (intensity of $15 \mathrm{~mW} / \mathrm{cm}^{2} / \mathrm{s}$ ) in 24-well plates without a lid for a total of $2 \mathrm{~h}$. A portion of the culture was plated onto $\mathrm{KB}$ agar to ensure absence of any viable CFU. Plates were incubated at $28^{\circ} \mathrm{C}$ for the first $48 \mathrm{~h}$ and then room temperature for the subsequent 5 days. No growth was detected from UV-killed isolates (Supplementary Fig. S1). Bacteria were applied to seeds as above. After inoculation of Pseudomonas syringae pv. tomato, disease was monitored for 8 days.

Tomato seedling growth. In all experiments, seedlings were grown on $1 \%$ agar plates. Inoculated seeds were kept in the dark at $21^{\circ} \mathrm{C}$ for 6 days and transferred into a growth chamber at $25^{\circ} \mathrm{C}, 65 \%$ humidity and $16 \mathrm{~h}$ daylight per day for 2 days until challenged with Pseudomonas syringae pv. tomato strain DC3000 (described below in flooding assay).

Pathogen flooding assay. The pathogen used in this work is Pseudomonas syringae pv. tomato strain DC3000. To challenge the seedlings with the pathogen, we modified a previous $P$ seudomonas syringae flooding assay (Hassan et al. 2017). Pseudomonas syringae pv. tomato was grown overnight in $\mathrm{KB}$ at $28^{\circ} \mathrm{C}$, and $\mathrm{OD}_{600}$ was measured of the overnight culture. The culture was diluted to $\mathrm{OD}_{600}=0.0002$ in sterile $10 \mathrm{mM} \mathrm{MgCl}_{2}$ solution, representing approximately $5 \times 10^{3} \mathrm{CFU} / \mathrm{ml}$. We further added Silwet at $0.015 \%$ by volume to the diluted culture to ensure even dispersal of the pathogen. We flooded each $1 \%$ water agar plate of seedlings with $6 \mathrm{ml}$ of the final Pseudomonas syringae pv. tomato culture. The Pseudomonas syringae pv. tomato culture was deposited directly on top of cotyledon leaves to ensure contact between Pseudomonas syringae pv. tomato and the leaf surface. Flooded plates were shaken gently on an orbital shaker for $4 \mathrm{~min}$; the liquid was then poured off of the plates. For negative control seedlings, sterile $10 \mathrm{mM} \mathrm{MgCl}_{2}$ solution was used in place of Pseudomonas syringae pv. tomato culture. Infected tomato seedlings were kept vertically with cotyledons up in growth chamber at $25^{\circ} \mathrm{C}, 65 \%$ humidity and $16 \mathrm{~h}$ daylight per day until final collection. For the pathogen dose response curve, seedlings were flooded with Pseudomonas syringae pv. tomato density ranging from $\mathrm{OD}_{600}$ of $2 \times 10^{-5}$ to $2 \times 10^{-2}$.

Disease severity scoring. Each experimental replicate plate held four to six seedlings (Supplementary Fig. S2). The disease symptoms of every individual seedling were scored daily after flooding until the final collection. All seedlings were randomly assigned numbers and scored blindly for every experiment. The duration of experiments ranged from 8 to 14 days (see $\mathrm{x}$-axis of figures, and methods above, for details). As has been done in previous plant disease assays (Song et al. 2017; Rajendran et al. 2016), we established a series of disease symptom scores that correspond to different levels of disease severity, with chlorosis and speckling as the two primary symptoms. To optimize both the descriptive power and the accuracy of our scoring, we set the following scoring indices: $1=$ mildly diseased, 2 = moderately diseased, 3 = severely diseased, and $4=$ loss of leaf or death. Individual seedlings were scored blind daily for the duration of the experiments. Seedlings within one experimental replicate were then pooled into one 15-ml conical and processed as described below. Disease severities of individual seedlings within an experimental replicate were averaged, and these data are displayed as a single data point to avoid problems of pseudo-replication. We analyzed these data in two ways. First, we used repeated measures generalized linear model to analyze disease progression of individual experimental replicates over time. We then calculated the area under the disease progression curve (AUDPC) (Madden et al. 2007) as a cumulative measure of disease symptoms over time, and analyzed treatment effects using analysis of variance (ANOVA).

Seedling collection and processing. Seedlings from each experimental replicate were collected with sterile forceps and combined into $15-\mathrm{ml}$ conical tubes and weighed. Seedlings were submerged in $5 \mathrm{ml}$ of sterile $10 \mathrm{mM} \mathrm{MgCl}$ solution, homogenized with round ceramic beads for $40 \mathrm{~s}$ at $4 \mathrm{~m} / \mathrm{s}$ for $35 \mathrm{~s}$ using a Fastprep-24 5G. The final homogenates had little or no large visible plant material. 
ddPCR quantification of bacteria. Pseudomonas syringae density was quantified from each experimental replicate using droplet digital PCR using a fluorescent probe targeting the Pseudomonas 16S gene (Bergmark et al. 2012) as fully described elsewhere (Morella et al. 2018). Briefly, seedling homogenates were diluted 1:10, and $2 \mu \mathrm{l}$ of homogenate was used as template in the BioRad QX200 ddPCR reaction. In analyzing positive droplets, all thresholds were set using negative, no template controls and positive pure Pseudomonas syringae pv. tomato DNA controls. As with analysis of AUDPC, Pseudomonas syringae pv. tomato densities are a measure of each plate experimental replicate, as described above. Bacterial abundances are normalized to total seedling weight within a plate and reported as copy of 16S rRNA gene per gram of plant material. For negative ddPCR controls, we always attempted to measure Pseudomonas syringae pv. tomato in the $\mathrm{MgCl}_{2}$ inoculated plant controls for all experiments as well as Pantoea DNA. Although the Pseudomonas syringae pv. tomato probe was designed to be specific to Pseudomonads, we did this to ensure our probe was only amplifying Pseudomonas syringae pv. tomato and not Pantoea nor any plant material. The signal amplitudes for sterile plant-only and Pantoea isolates-only controls were the same as those of no-template, sterile $\mathrm{ddH}_{2} \mathrm{O}$ controls, indicating that indeed, there was no detectable background amplification of Pantoea species when using the Pseudomonas probe, and no Pseudomonas was present in the negative controls.

DNA extraction of isolates and community. Homogenized seedling material was used for DNA extractions for community profiling using the Qiagen PowerSoil DNA extraction kit. For bacterial isolates, DNA was extracted using the Qiagen Blood and Tissue kit protocol for gram-negative bacteria.

DNA extractions of all bacterial isolates from the seed wash were performed using the QIAGEN DNeasy Blood \& Tissue Kit. Samples were taken with sterile pipet tips from axenic colonies. We followed the kit's accompanying protocol for DNA extractions of gram-negative bacteria. Success of extraction was verified by NanoDrop nucleotide quantification.

$16 \mathrm{~S}$ amplicon sequencing of the seedling communities. The $16 \mathrm{~S}$ rRNA gene was amplified using dual-indexed primers designed for the V3-V4 region (Naylor et al. 2017) using the following primers: $341 \mathrm{~F}$ (5-CCTACGGGNBGCASCAG-3) and 785R (5GACTACNVGGGTATCTAATCC-3) (Takahashi et al. 2014). Additionally, we used peptide nucleic acids, PNAs (Lundberg et al. 2013) to decrease amplification of plant mitochondrial and chloroplast DNA. For community profiling, we also sequenced a DNA extraction of the reagents from the DNA extraction kit and our negative PCR control along with experimental samples. Reaction conditions were $94^{\circ} \mathrm{C}$ for $3 \mathrm{~min}, 94^{\circ} \mathrm{C}$ for $45 \mathrm{~s}, 78^{\circ} \mathrm{C}$ for $10 \mathrm{~s}, 50^{\circ} \mathrm{C}$ for $1 \mathrm{~min}, 72^{\circ} \mathrm{C}$ for $1.5 \mathrm{~min}$, repeat steps 2 to 530 times and $72^{\circ} \mathrm{C}$ for $10 \mathrm{~min}$. PCR mixtures were randomized in order, run in triplicate for each sample, pooled and quantified using Qubit. Amplicons from each sample were pooled in equimolar concentrations, cleaned using an AMpure bead clean-up kit. Libraries were prepared for paired 300-nucleotide reads in Illumina's MiSeq V3 platform (Illumina) at The California Institute for Quantitative Biosciences (QB3) at UC Berkeley and run in 1 lane.

Identification of bacterial isolates. Using pure DNA of individual bacterial isolates, we amplified and sequenced $16 \mathrm{~S}$ genes using $27 \mathrm{R}$ and $1492 \mathrm{R}$ primers (Weisburg et al. 1991). In addition to $16 \mathrm{~S}$, we sought to further discriminate against our potential strains, and so we amplified the $g y r B$ gene and $r p o B$ genes with previously published primers and PCR protocols (Brady et al. 2008; Delétoile et al. 2009). We performed a BLASTn search of all isolate sequences and recorded the top hits with the highest identity (Supplementary Table S1). Phylogenetic tree of isolates and neighbors were built using $\operatorname{gyr} B$ sequences. We placed our isolates within a subset of samples previously mapped in a Pantoea phylogenetic tree by Rezzonico et al. (2009). T. Smits (personal communication) provided the E325 gyrB sequence. The evolutionary history of our isolates and other strains was inferred by using the maximum likelihood method based on the Tamura-Nei model (Tamura and Nei 1993). The tree with the highest log likelihood is shown. Initial trees for the heuristic search were obtained automatically by applying neighbor-join and BioNJ algorithms to a matrix of pairwise distances estimated using the maximum composite likelihood (MCL) approach, and then selecting the topology with superior log likelihood value. The tree is drawn to scale, with branch lengths measured in the number of substitutions per site. The analysis involved 13 nucleotide sequences. All positions containing gaps and missing data were eliminated. There were a total of 316 positions in the final dataset. Evolutionary analyses were conducted in MEGA7 (Kumar et al. 2016).

Amplicon sequencing analysis. MiSeq sequencing files were demultiplexed by QB3 sequencing facility. Reads were combined into contigs using VSearch (Rognes et al. 2016), and the remainder of the analysis was carried out in Mothur version 1.41.3 (Schloss et al. 2009) following their MiSeq SOP (Kozich et al. 2013). Data were quality-filtered by length, ambiguous bases, and homopolymer length using the recommended Mothur parameters. Chimeras were removed using UChime (Edgar et al. 2011). We used a 99\% similarity cut-off for defining operational taxonomic units (OTUs). The Silva reference database (Quast et al. 2013) was used for sequence alignment and taxonomic assignment. Archaeal, chloroplast, mitochondrial and unknown domain DNA sequences were removed. Once an OTU table was generated in Mothur, the remainder of the analysis was performed in $\mathrm{R}$ using the Phyloseq package version 1.19.1 (McMurdie and Holmes 2013) and Vegan package version 2.4-5 (Dixon and Palmer 2003). To account for reagent contaminants, we also sequenced DNA extraction kit controls and PCR controls along with our samples. Contaminant OTUs from control samples that were at a similar or higher relative abundance in control samples compared with experimental samples were removed from the full OTU table. Data were rarified to 50,000 reads per sample and singletons were removed.

Statistical analysis. All statistical tests were done using R (version 3.4.4) and SPSS 24.0 (SPSS, Chicago, IL). Details of statistical tests and results are reported in the text. Graphs were plotted in $\mathrm{R}$ using the ggplot2 package version 2.2.1 (Wickham 2009). Individual data points represent the value averaged across seedlings within an experimental replicate.

\section{RESULTS}

Initial screening of protective effects of natural seed microbiota. To first determine if endogenous epiphytic microbiota of field tomato seeds are protective against pathogen infection, we germinated seeds with or without their endogenous epiphytic community from each of the four tomato types before challenging with Pseudomonas syringae pv. tomato and measuring disease severity (Fig. 1A and B). We found that the application of endogenous seed microbiome significantly reduces disease symptoms at the seedling stage (Fig. 1C; repeated measures GLM, $\mathrm{F}_{1,42}=5.182, P=$ 0.02327 ), and there is no significant effect of host tomato type on the protective effects of their microbiome $\left(\mathrm{F}_{3,42}=0.597, P=0.6212\right)$. There is also no significant interaction between disease severity and tomato type $\left(\mathrm{F}_{3,42}=0.807, P=0.4988\right)$.

As an alternative measure of disease, we also calculated the area under the disease progression curve (AUDPC) as a cumulative measure of disease symptoms over time (Fig. 1D). Seedlings with their original seed microbiome had significantly lower AUDPC 

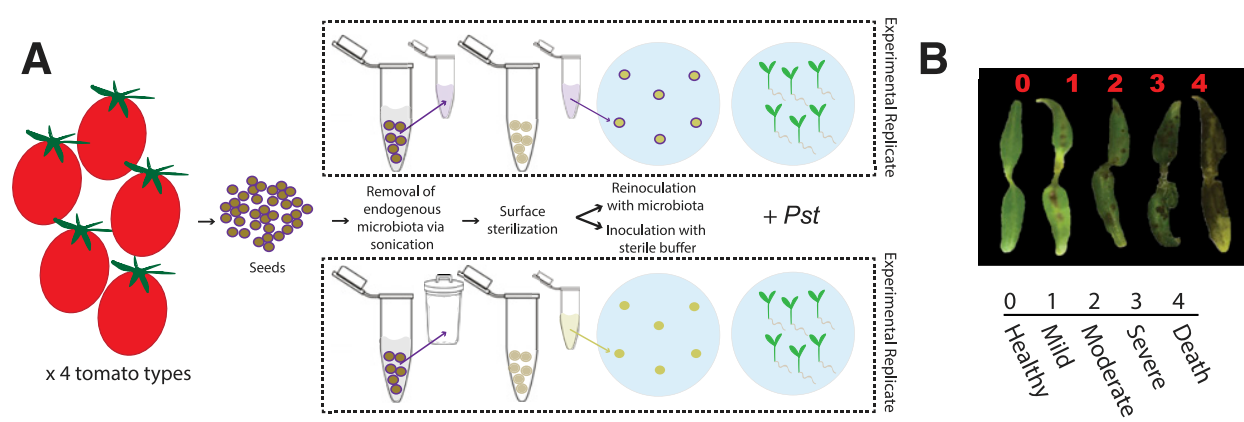

C
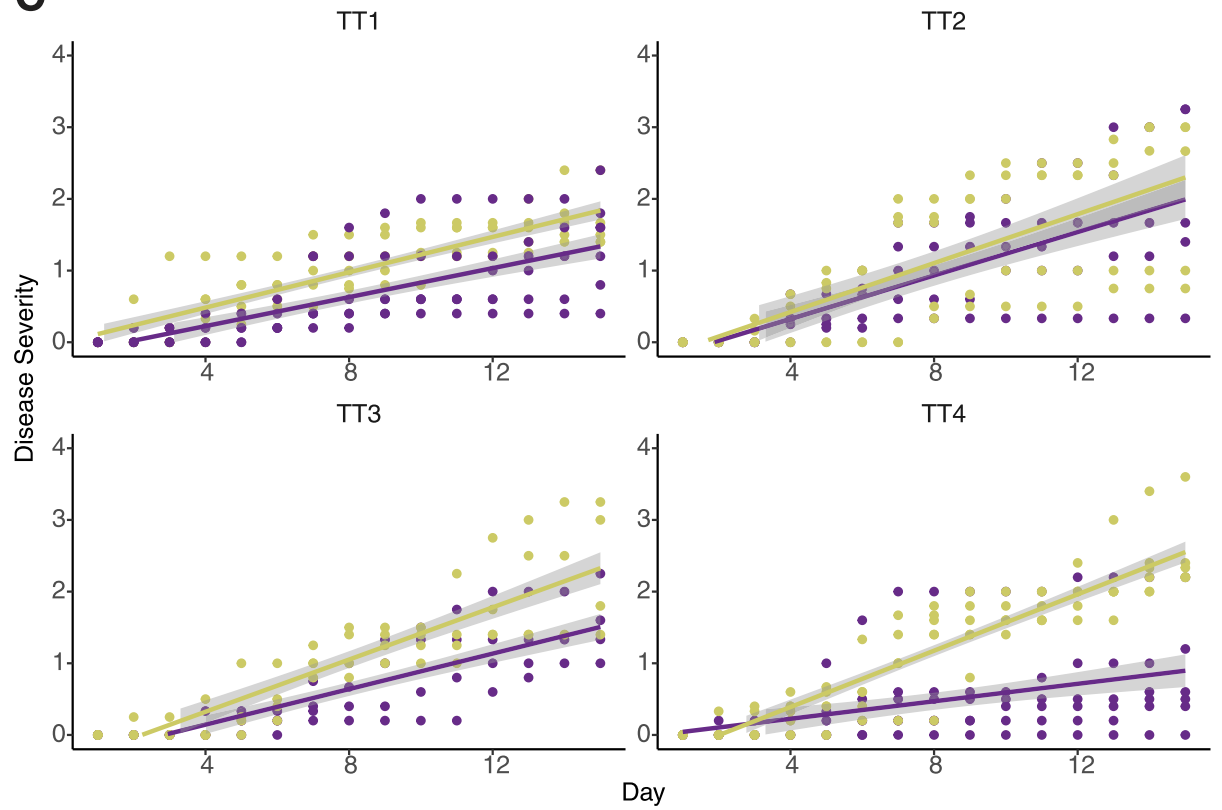

$\rightarrow$ With Endogenous Microbiota $=-$ Buffer

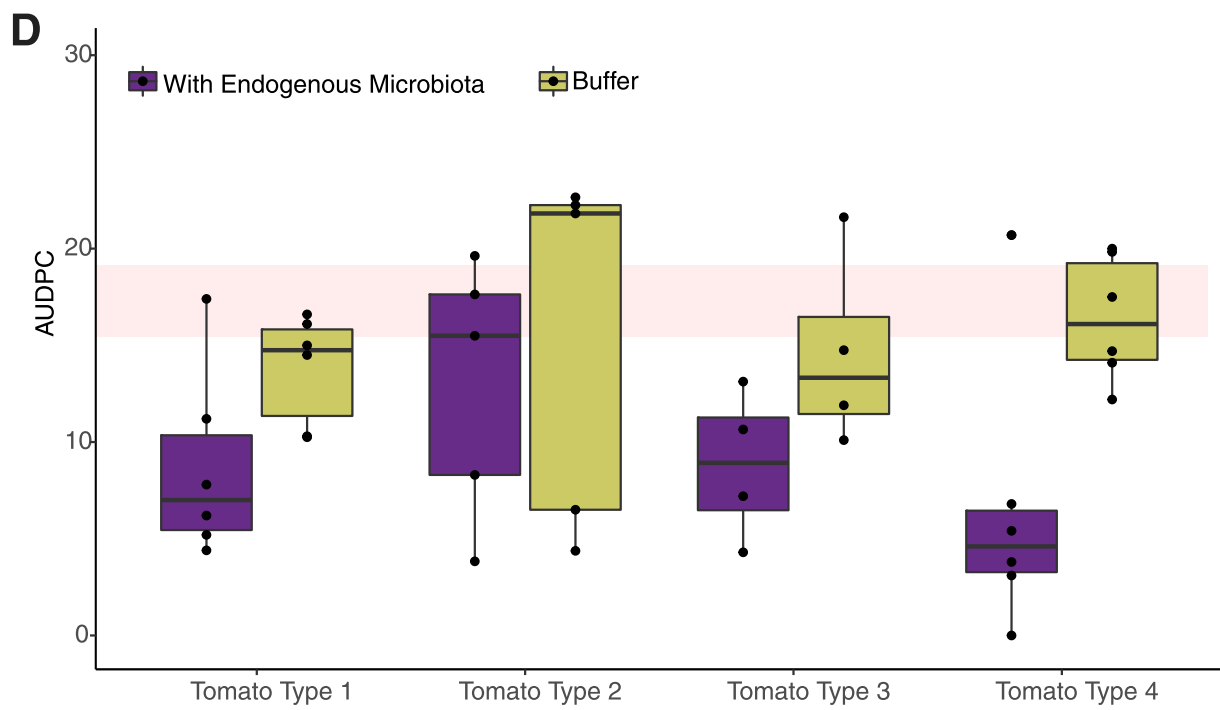

Fig. 1. Screening tomato seed microbiomes for protection against Pseudomonas syringae pv. tomato DC3000. Seeds from each tomato type, or biological replicate, were depleted of their epiphytic microbiome, sterilized, and then restored with their microbiome or not. A, Experimental replicates consisted of six seeds. B, After germination and challenge with the pathogen, a disease severity index was used to rate seedlings on a scale of 0 to 4 for four different seed microbiome sources. C, Disease severity was tracked for 15 days and averaged across seedlings within an experimental replicate, fit to a linear regression and plotted with confidence intervals (shading). D, Total area under the disease progression curve was calculated for replicates in each treatment and graphed as boxplots where black line indicates median, the upper portion of the box is third quartile, lower portion is first quartile, whiskers are maximum and minimum, and outliers are black dots. The red shaded area indicates an area under the disease progress curve (AUDPC) at which $50 \%$ or more of seedlings on a plate are dead (averaged across all treatments \pm standard error). 
values (ANOVA $\left.\mathrm{F}_{1,34}=11.310, P=0.0019\right)$, and alleviation of disease severity is again largely independent of the tomato type $\left(\mathrm{F}_{3,34}=0.612, P=0.612\right)$. There was no significant interaction between the two variables $\left(\mathrm{F}_{3,34}=0.758, P=0.5252\right)$.

Application of protective TT4 seed microbiota across multiple tomato types. We next sought to test the protective effects of the seed microbiome independent of the host genetic background. We chose to use TT4 because, based on our initial results, it appeared to have the strongest protective effect. We harvested the TT4 seed microbiome from TT4 seeds and applied it onto surface-sterilized seeds of both itself and the other two tomato types (with the exception of tomato type 3, as an insufficient number of tomatoes were collected from the field to conduct the experiment). We found that TT4 seed microbiota was also capable of protecting tomato types 1 and 2 from disease. The application of TT4 microbiome is significantly protective against Pseudomonas syringae pv. tomato infection when the disease progression data were compared with controls $\left(\mathrm{F}_{1,21}=\right.$ 16.531, $P=0.0006$; Fig. 2A). There was also a significant effect of recipient tomato type $\left(\mathrm{F}_{2,21}=4.852, P=0.018\right)$, but no interaction between tomato type and treatment was observed $\left(\mathrm{F}_{2,21}=0.481, P=\right.$ 0.625). When analyzing the same data using AUDPC value (Fig. 2B), we similarly observed that seedlings that received TT4 microbiota are significantly less diseased $\left(\mathrm{F}_{1,21}=16.234, P=0.0006\right.$; Fig. $\left.2 \mathrm{~B}\right)$. Again, there is a significant effect of recipient genotype $\left(\mathrm{F}_{2,21}=\right.$ 4.355, $P=0.0261$ ), but with no significant interaction between the two variables $\left(\mathrm{F}_{2,21}=0.278, P=0.7604\right)$.

In addition to analyzing disease severity, we used ddPCR to quantify total Pseudomonas syringae pv. tomato density from the seedlings at the end of the experiment. We found that seedlings that did not receive TT4 microbiota carried significantly more Pseudomonas syringae pv. tomato than those that $\operatorname{did}\left(\mathrm{F}_{1,17}=11.237, P=\right.$ 0.0038) (Fig. 2C). Unlike disease progression, we did not detect any effect of recipient tomato type on Pseudomonas syringae pv. tomato density $\left(\mathrm{F}_{2,17}=0.966, P=0.4007\right)$ and there was not an interaction among tomato type and treatment $\left(\mathrm{F}_{2,17}=0.784, P=0.472\right)$.

Taxonomic characterization of seedling microbiota. Intrigued as to what made TT4 seed microbiota protective on not only its own tomato genotype but also others, we used 16S rRNA community profiling to sequence the bacterial communities of two week old seedlings whose seeds had been inoculated with TT4 microbiota. We found that these seedlings were strikingly dominated by OTUs in the genus Pantoea (Fig. 3A). Knowing that Pantoea is highly culturable, and also that many species are already used as biocontrol strains (Walterson and Stavrinides 2015), we next sought to culture isolates from TT4 seeds to determine the exact species of Pantoea that were endogenously found on these seeds. We were able to culture six bacterial isolates from TT4 seeds. We also tried to culture bacterial isolates from the other three tomato types, and we were only able to culture one bacterial isolate from TT2, which we identified as a Bacillus species (G1A). Using Sanger sequencing, we sequenced the $16 \mathrm{~S}$ genes of our isolates and identified them as species of Pantoea. Because Pantoea spp. are notoriously difficult to differentiate using $16 \mathrm{~S}$ sequences (Brady et al. 2008; Delétoile et al. 2009), we chose three isolates (ZM1, ZM2, and ZM3) based on distinct colony morphology and different $16 \mathrm{~S}$ sequences, and sequenced their gyr $B$ and $r p o B$ genes as well. We were able to further confirm their identities and place them within a phylogenetic tree of Pantoea spp. (Fig. 3B) (Rezzonico et al. 2009). To our knowledge, our isolates have not been previously identified nor used as biocontrol strains, although some related strains have been developed (Fig. 3B, noted as "Biocontrol"). Interestingly, ZM3 and ZM2 appear to be similar based on DNA sequencing, with their partial $16 \mathrm{~S}$ sequences aligning $99 \%$ to one another and their partial gyrB sequences aligning $100 \%$. However, when grown on nutrient agar, their colonies are distinctly different colors; yellow and white, respectively. Whole genome sequences will further elucidate genetic differences between the isolates and are currently underway. Lastly, we aligned our $\sim 420$ bp of amplicon sequencing data to near full length reverse Sanger sequencing reads of the isolates and observed $100 \%$ match of some of these OTUs with our isolate sequences (Fig. 3B; Supplementary Table S2).

Protective ability of seed microbiota isolates and known biocontrol strains. Next, we sought to determine if the isolates alone, in the absence of the remaining microbiome, were sufficient in protecting seedlings against disease. We evaluated the protective ability of ZM2, ZM3, two commercially available biocontrol agents of the same genus, and the putative Bacillus spp. (GIA) that we cultured from the less protective TT2 seed microbiome. Treatments were categorized as the following treatments: single-strain, consortia, or control. When comparing AUDPC values after 10 days of disease scoring (Fig. 4A), we found a significant effect of treatment $\left(F_{2,30}=\right.$ 12.01, $P<0.0001)$. Posthoc Tukey tests show both single-strain inoculated seedlings and consortia inoculated seedlings were significantly less diseased than seedlings which did not receive any bacteria $(P=0.0001$ and $P<0.0001$, respectively). There was no significant difference between seedlings inoculated with single strains and consortia $(P=0.89)$. We also uncovered a significant effect of strain $\left(\mathrm{F}_{5,12}=5.07, P=0.01\right)$. Posthoc Tukey tests revealed that the only significant differences among strains are between strains ZM1 and G1 A $(P=0.03)$ and strains ZM2 and G1A $(P=0.007)$.

When analyzing Pseudomonas syringae pv. tomato density (Fig. 4B), we again found a significant effect of treatment $\left(\mathrm{F}_{2,30}=32.29\right.$, $P<0$ 0.0001). Posthoc Tukey tests show both single-strain inoculated seedlings and consortia inoculated seedlings were significantly less diseased than seedlings which did not receive any bacteria $(P<0.0001)$. There was no significant difference between seedlings inoculated with single strains and consortia $(P=0.73)$.

Unlike AUDPC, there was no significant effect of strain in terms of total pathogen load $\left(\mathrm{F}_{9,22}=1.094, P=0.412\right)$.

We next compared the protective ability of live isolates compared with their UV-killed counterparts (Fig. 4C and D). When analyzing the effect on disease severity via AUDPC values, we found a significant effect of both UV-treatment $\left(\mathrm{F}_{1,26}=69.3786, P<\right.$ $0.00001)$ and isolate treatment $\left(\mathrm{F}_{6,26}=6.9200, P=0.00018\right)$. There was no significant interaction of the two $\left(\mathrm{F}_{6,26}=1.1786, P=\right.$ 0.34644). When analyzing Pseudomonas syringae pv. tomato density, we observed a significant effect of isolate treatment $\left(\mathrm{F}_{6,26}=\right.$ $10.151, P<0.00001)$, but we did not observe an overall significant effect of UV-treatment $\left(\mathrm{F}_{1,26}=0.443, P=0.512\right)$. Again, there was no significant interaction between isolate and $\mathrm{UV}$-treatment $\left(\mathrm{F}_{6,26}=\right.$ $0.838, P=0.535$ ).

In order to determine if pair-wise differences existed between seedlings treated with live and UV-killed isolates and the notreatment control seedlings, we performed Welch's $t$ tests and controlled for multiple comparisons using the Bonferroni correction. For live bacteria, all isolates were capable of lowering disease severity symptoms compared with controls $(P<0.026)$. In contrast, we found that all Pantoea isolates were capable of lowering Pseudomonas syringae pv. tomato density $(P<0.048)$, but $E$. coli was not $(P=0.123)$. None of the UV-killed isolates lowered AUDPC values compared with controls $(P>0.068)$. In contrast, we find that ZM1, ZM2, ZM3, and E325 significantly lower Pseudomonas syringae pv. tomato density $(P=0.04104,0.03783$, 0.03246 , and 0.04104 , respectively), and C9-1 and E. coli do not $(P=0.08417$ and 0.08242$)$. In conclusion, when comparing to 


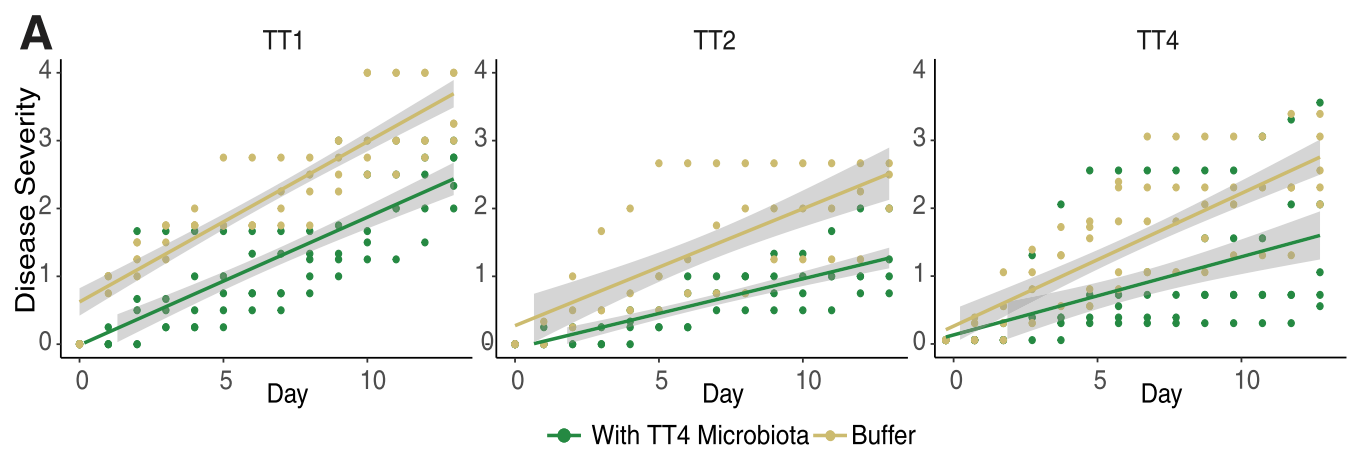

B With Microbiota from Tomato Type 4 Buffer
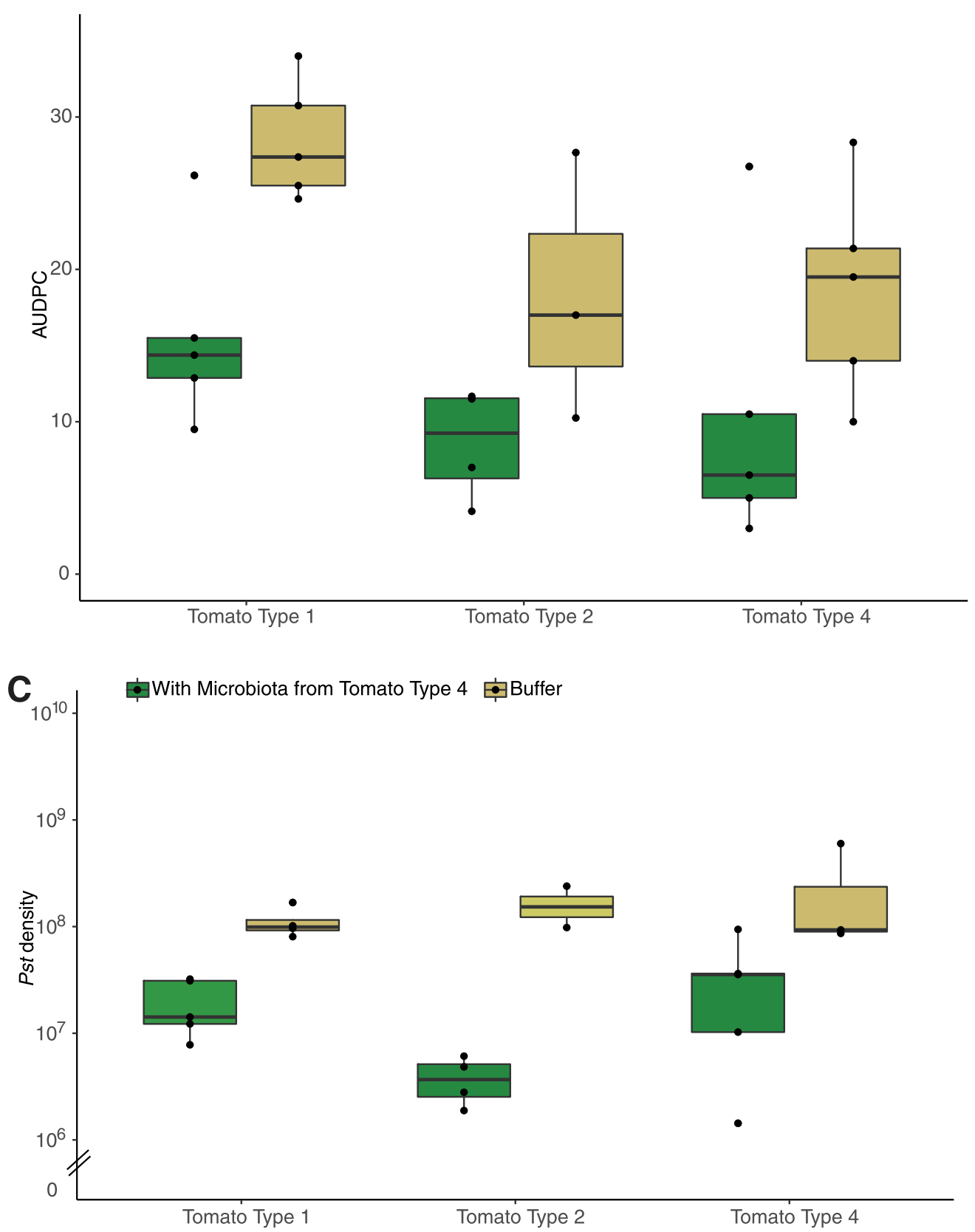

Fig. 2. Application of protective Tomato Type 4 (TT4) seed microbiota to multiple tomato types. A, TT4 microbiota was applied to three different tomato types (1, 2, and 4), challenged with Pseudomonas syringae pv. tomato, and disease severity was tracked for 14 days. B, Total area under the disease progression curve was calculated for replicates in each treatment and graphed as boxplots, where black line indicates median, the upper portion of the box is third quartile, lower portion is first quartile, whiskers are maximum and minimum, and outliers are black dots. C, Pseudomonas syringae pv. tomato density was measured using droplet digital PCR and plotted as boxplots. Pseudomonas syringae pv. tomato density is displayed as Pseudomonas $16 \mathrm{~S}$ copy number/gram of seedling. Note the $y$-axis begins at $10^{6}$. 
no-treatment control plants, all strains of live bacteria are capable of reducing disease severity, and all strains except for E. coli also lower Pseudomonas syringae pv. tomato density. In comparison, when seeds are treated with UV-killed bacterial strains, none lower disease severity, but all except for one Pantoea isolate and E. coli can still lower Pseudomonas syringae pv. tomato density.
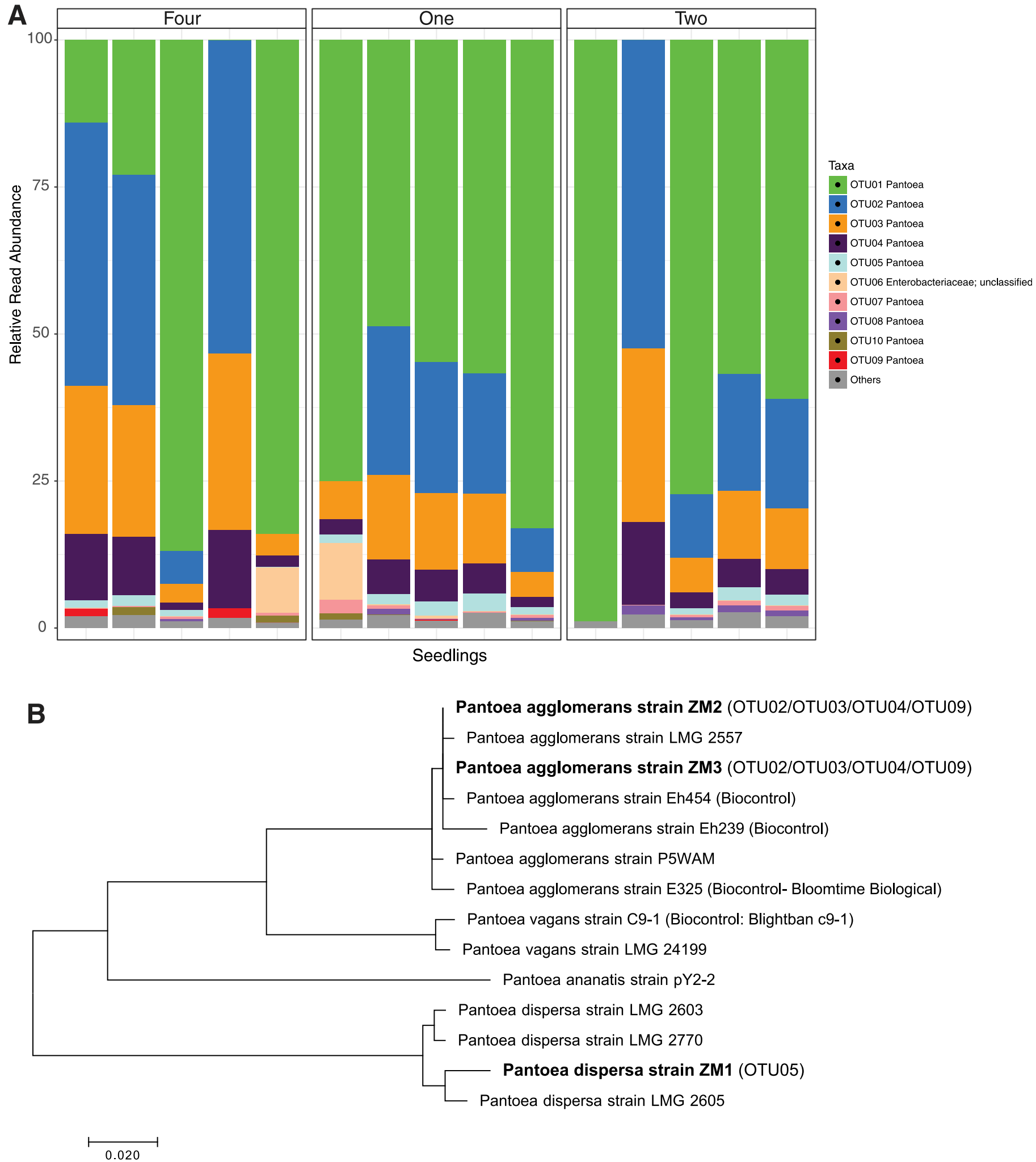

Fig. 3. Taxonomic characterization of Tomato Type 4 (TT4) seedling microbiota. A, Relative abundance of top operational taxonomic units (OTUs) in seedlings that were inoculated with TT4 complete microbiomes are displayed, with different colors representing different $99 \%$ cutoff OTUs. B, Isolated Pantoea strains are placed within a phylogenetic tree using the maximum likelihood method based on the Tamura-Nei model. Pantoea isolated in this study are bolded and known biocontrol strains are labeled as "Biocontrol". Details of tree building are included in methods. The OTUs whose sequences aligned $100 \%$ to the $16 \mathrm{~S}$ Sanger sequences are indicated after the isolate name. 
Pathogen dose response curves. We next determined the dosedependence of protection by varying Pseudomonas syringae pv. tomato density at inoculation from an $\mathrm{OD}_{600}$ of $2 \times 10^{-5}$ to $2 \times 10^{-2}$ in an effort to capture both the low end and high end of infection. We tested our three isolates in addition to the two commercially available Pantoea strains. As previously, we measured both disease severity and overall Pseudomonas syringae pv. tomato density (Supplementary Fig. S3). We found that disease severity and infection dosage are positively correlated (GLM, adjusted $R^{2}=0.7$, $\left.\mathrm{F}_{11,48}=13.31, P<00.0001\right)$. Both the seed inoculum treatment $\left(\mathrm{F}_{5,48}=20.08, P<0.0001\right)$ and infection dosage $\left(\mathrm{F}_{1,48}=38.58, P<\right.$ $0.0001)$ had significant effects on disease severity, with no significant interaction between the two $\left(\mathrm{F}_{5,48}=2.281, P<0.0612\right)$. Posthoc Tukey tests reveal that all treatments are significantly less diseased than the no-treatment controls $(P<0.006)$, and ZM1 is significantly more protective than both E325 $(P=0.02)$ and ZM3 $(P=0.04)$.
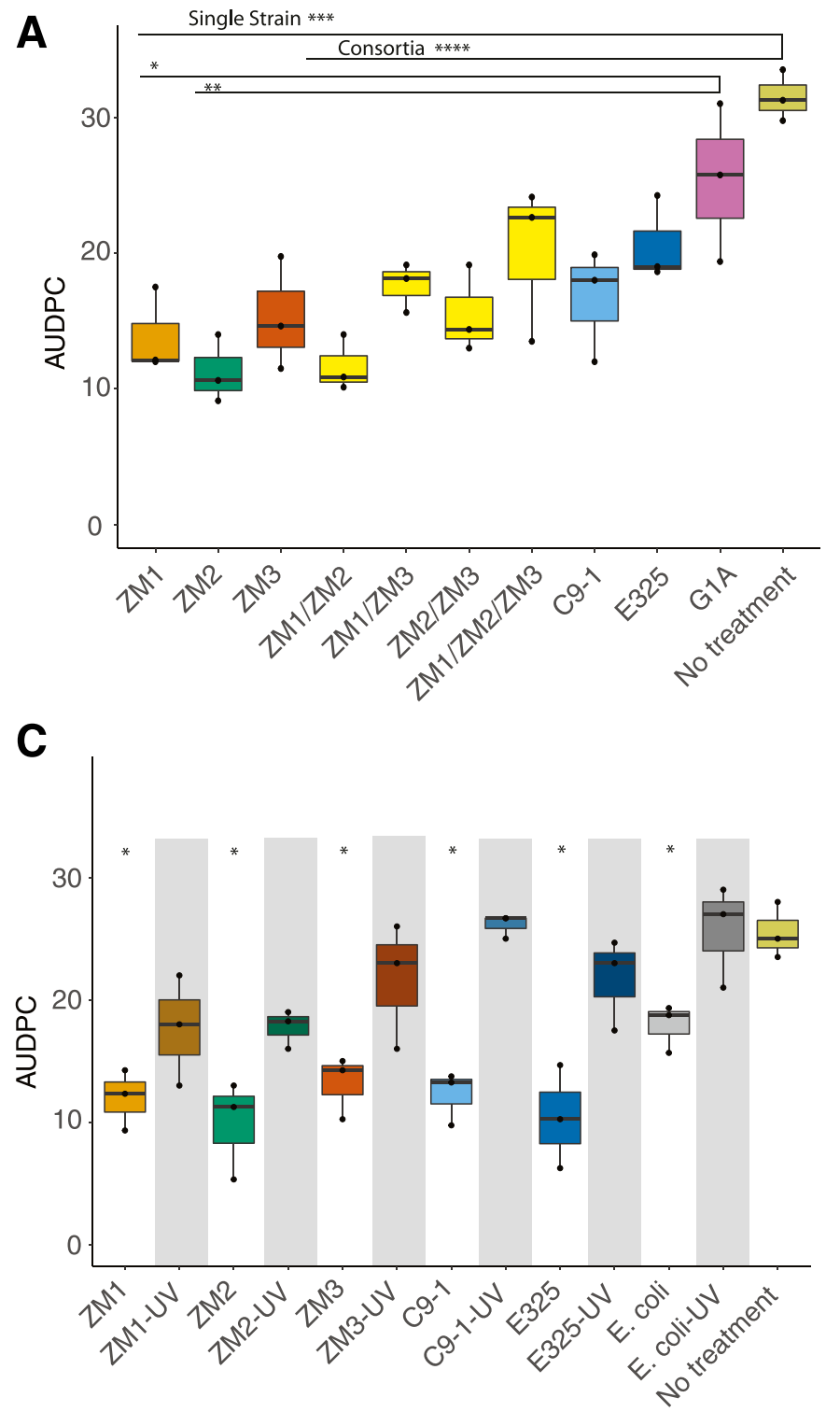

Pseudomonas syringae pv. tomato densities on seedlings were also linearly correlated with infection dose, although weakly so (GLM, adjusted $R^{2}=0.4, P=0.0003$ ). Like AUDPC values, bacterial isolate $\left(\mathrm{F}_{5,48}=6.5743, P<0.001\right)$ and dose $\left(\mathrm{F}_{1,48}=\right.$ $17.882, P=0.001$ ) had significant effects on Pseudomonas syringae pv. tomato densities. Here, we observe a significant interaction between the two $\left(\mathrm{F}_{5,48}=7.486, P<0.001\right)$, with negative controls having significantly more disease than every treatment $(P<0.01)$ except for E325 $(P=0.7383)$.

Protective isolate dose response curves. We varied the dose of Pantoea strains from $4 \times 10^{-1}$ to $4 \times 10^{6} \mathrm{CFU} /$ seed. Given they were cultured from TT4 seeds at an average of $40 \mathrm{CFU} / \mathrm{seed}$ (dashed vertical line, Fig. 5), this range captured 5 orders of magnitude above and 2 orders of magnitude below the biologically relevant abundance. After inoculation, we recorded disease severity of seedlings for 9 days, and calculated AUDPC (Fig. 5A) and overall Pseudomonas syringae pv. tomato density (Fig. 5B) (Supplementary Fig. S4).
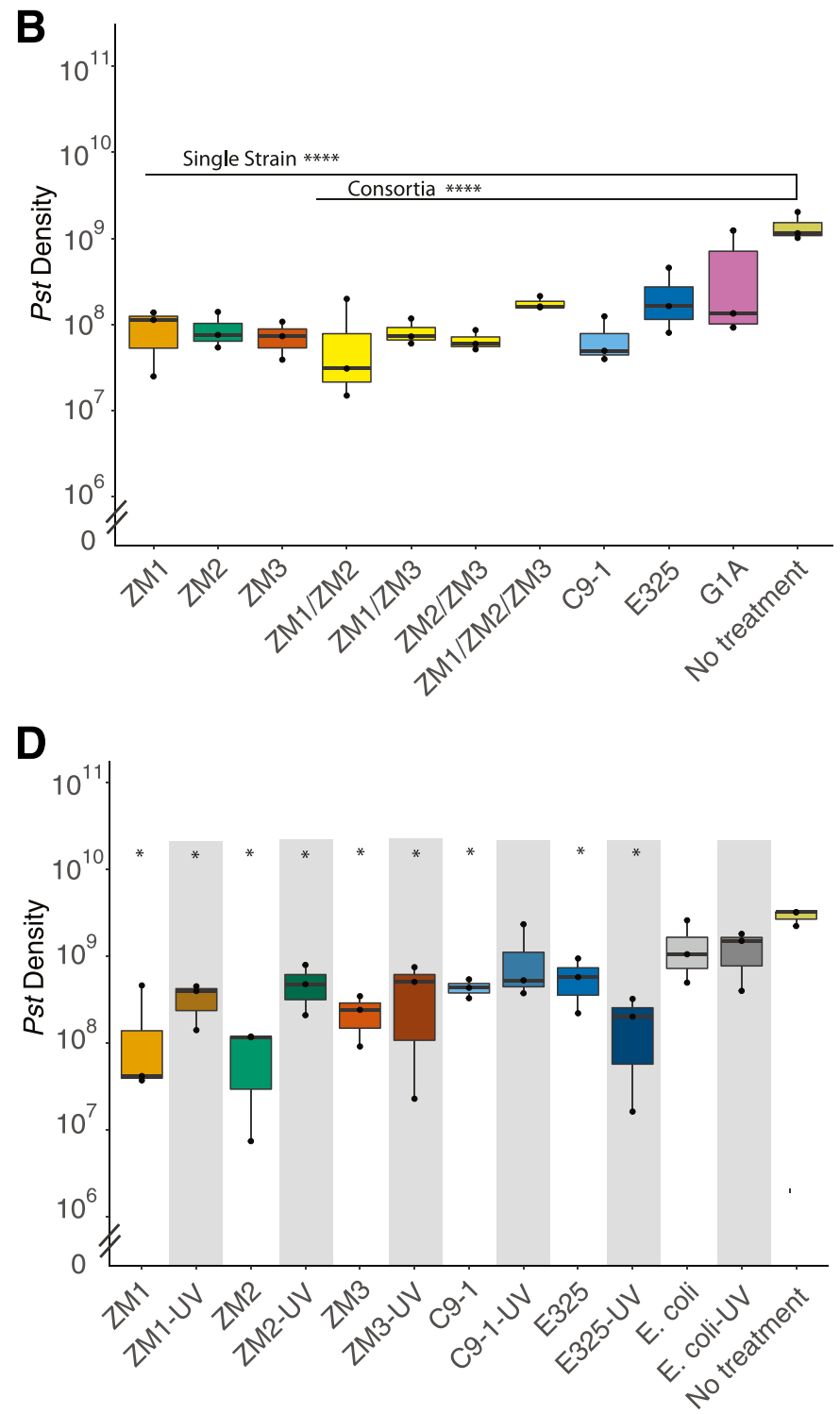

Fig. 4. Protective ability of bacterial isolates and known biocontrol strains. Money Maker seeds were inoculated with all isolates, combination of isolates, or sterile buffer "no treatment" control and challenged with Pseudomonas syringae pv. tomato and disease severity was tracked. A, Area under the disease progress curve (AUDPC) was calculated for each replicate and was compared across isolates. B, Pseudomonas syringae pv. tomato densities for all treatments were also measured. The protective ability of UV-killed strains was also tested. C, AUDPC was calculated, and D, Pseudomonas syringae pv. tomato density was measured. Note the $y$-axis begins at $10^{6}$. $\mathbf{C}$ and $\mathbf{D}$, Significance values indicate results of a Welch's $t$ test comparison with no-treatment controls with a correction for multiple comparisons. ${ }^{*}, P \leq 0.05 ;{ }^{\star \star}, P \leq 0.01 ;{ }^{* \star \star}, P \leq 0.001 ;$ and ${ }^{* \star \star \star}, P \leq 0.0001$. 
Seedlings that were inoculated with sterile buffer had an average AUDPC of $29 \pm 2.3$ and overall Pseudomonas syringae pv. tomato density of $9.96 \times 10^{9} \pm 1.07 \times 10^{9}$ copies/gram (gray dashed horizontal lines). Treatment at all doses, with the exception of a handful of very low density treatments, were effective at reducing both disease severity and Pseudomonas syringae pv. tomato density compared with seedlings that did not receive any protective bacteria. With regard to disease severity, AUDPC values negatively correlated with inoculation densities significantly (adjusted $R^{2}=0.7999, P<$ 0.0001 ), and there is a significant effect of treatment type on disease severity outcomes (ANOVA, $\mathrm{F}_{4,65}=32.973, P<0.0001$ ). However, there is no linear relationship between final Pseudomonas syringae pv. tomato density and inoculation densities (adjusted $R^{2}=0.0948$, $\left.\mathrm{F}_{9,65}=1.861, P=0.0740\right)$. In this case, a cubic model was the best fit to our data (adjusted $R^{2}=0.6567, \mathrm{~F}_{19,55}=8.449, P<0.0001$ ). Under this model, we found that isolate type had a marginally significant effect on final Pseudomonas syringae pv. tomato density (ANOVA, $\left.\mathrm{F}_{4,55}=2.4836, P=0.05414\right)$.
In order to determine if the lowest Pseudomonas syringae pv. tomato values we observed were statistically different across doses, we used a SPLINE model to (i) fit a cubic model to the data (curved line); (ii) identify the minimum value on the curve (horizontal line); and (iii) identify the distribution of the minimum value (shaded area). We found that for all three of our isolates, the distribution around the calculated minimum Pseudomonas syringae pv. tomato density encompasses the concentration at which isolates were originally cultured for TT4 seedlings (diamond data points).

\section{DISCUSSION}

Through a combination of culture-dependent and independent methods, we were able to directly test the protective effects of naturally occurring seed-associated microbiota, both in consortia and as single isolates. We found one particularly protective seedassociated microbial community that was able to significantly decrease the density of Pseudomonas syringae pv. tomato DC3000
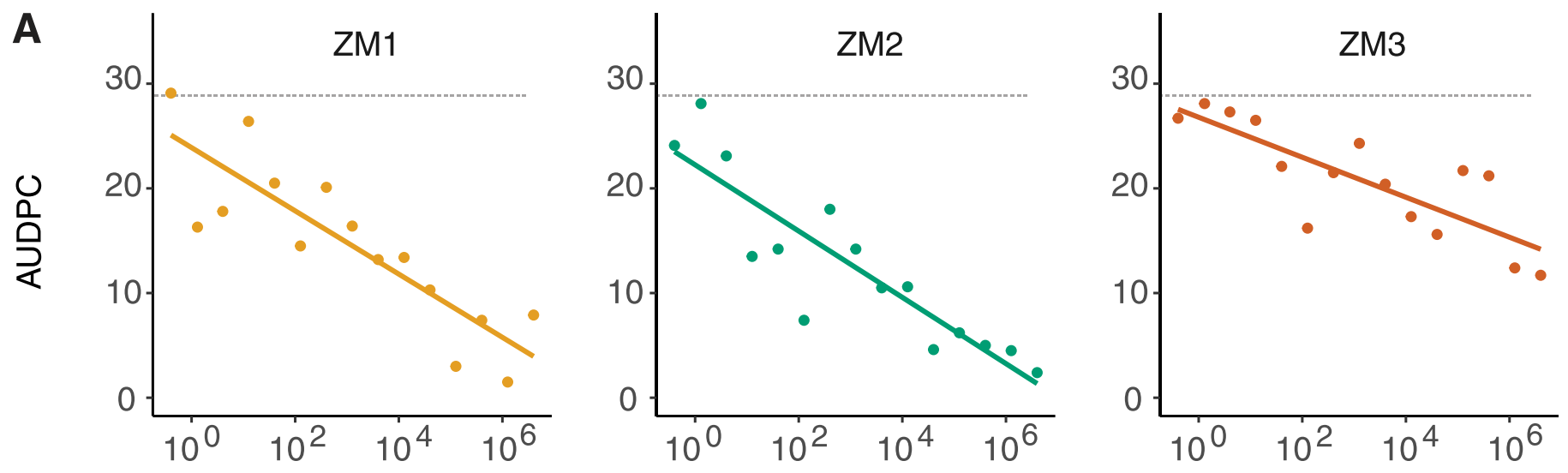

\section{Inoculum Concentration, CFU/seed}
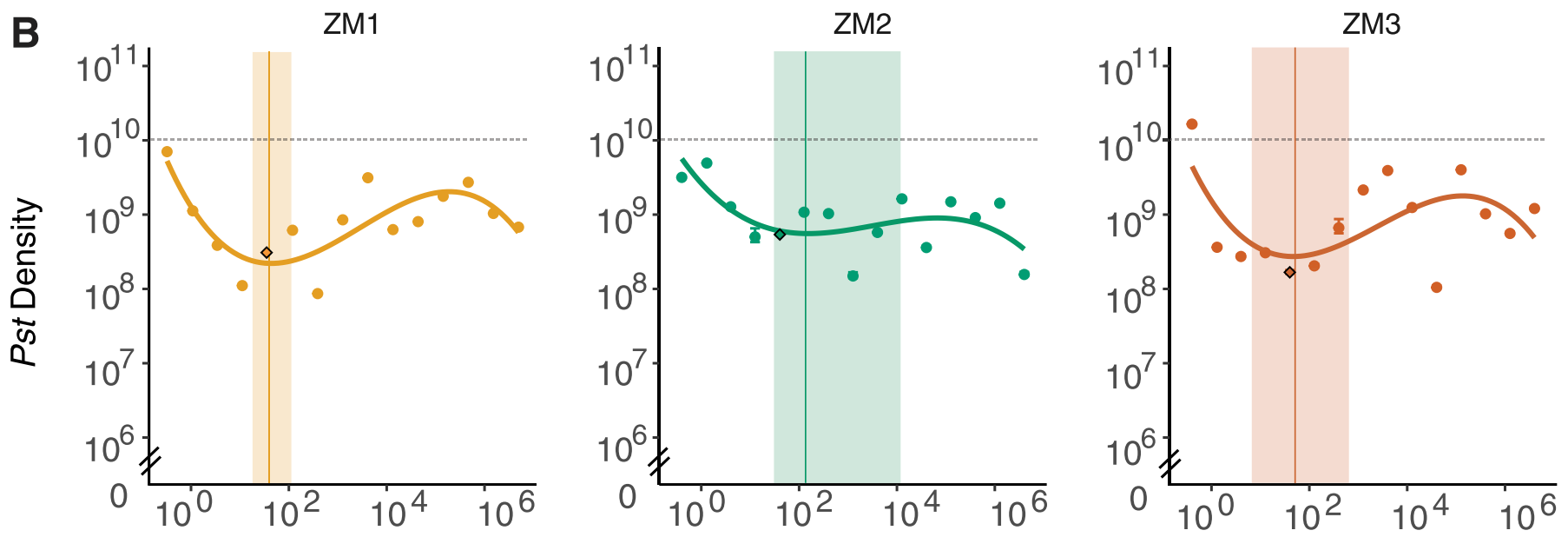

\section{Inoculum Concentration, CFU/seed}

Fig. 5. Pantoea dose response curve. Seeds were inoculated with varying densities of protective strains, challenged with Pseudomonas syringae pv. tomato and disease severity was tracked for 9 days. A, Area under the disease progress curve (AUDPC) was calculated, and a linear model was fit to the data. The dashed horizontal line indicates the mean AUDPC of control seedlings that did not receive any treatment of protective isolates. B, Pseudomonas syringae pv. tomato densities were also measured. A cubic model was fit to the data (curved line). The vertical dashed line indicates the predicted minimum value from a SPLINE model used on a cubic fit to the data; the shaded area indicates the distribution of the minimum range. The diamond data point outlined in black indicates the concentration at which Pantoea was originally cultured off the seedlings. Error bars represent the Poisson error of the double-distilled (dd)PCR measurement of Pseudomonas syringae pv. tomato density. Pseudomonas syringae pv. tomato density is displayed as Pseudomonas $16 \mathrm{~S}$ copy number/gram of seedling. Note the y-axis begins at $10^{6}$. 
growth on seedlings and reduce disease symptoms across multiple tomato types. Community profiling uncovered that Pantoea spp. dominated this seed microbiome, regardless of which seedling type it was applied to, and we were able to culture specific Pantoea strains directly from the surface of these seeds. When we applied these culturable isolates to seeds, we found that individual strains were as protective when applied in isolation as when combined. In order to understand how application density impacts protection, we varied the dose of isolates ZM1, ZM2, and ZM3, and we found a nonlinear pattern of inoculation density correlation with pathogen density.

The seed surface is the primary site of contact between seed and fruits, and it is known to harbor a diversity of microbes across plant species. Despite this, few studies have included seed epiphytes when investigating seed-associated microbes, focusing primarily on seed endophytes (reviewed in Truyens et al. 2015). Studies on seedassociated endophytes in maize (Johnston-Monje and Raizada 2011), cucurbits (Khalaf and Raizada 2016), and rice (Hardoim et al. 2012) have revealed both high microbial diversity and the presence of conserved genera across geographical, ecological, and host genotypic variations. In maize, seed-associated bacterial communities vary in accordance with host phylogeny, suggesting a close evolutionary partnership between the conserved microbiota and host plants (Johnston-Monje and Raizada 2011). Moreover, seed-associated microbiota can successfully colonize seedlings, although their community structure has been shown to change as seedlings develop (Barret et al. 2015). Pairwise assays have also shown that certain individual isolates from seed endophytic communities can interact antagonistically to pathogens in eucalyptus (Ferreira et al. 2008), rice (Cottyn et al. 2009), and cucurbit seedlings (Khalaf and Raizada 2018), acting as key diseaseresisting members. More recently, a study on the seed microbiota of Brassica napus revealed that inoculating seeds with bacterial strains can lead to resistance against a fungal pathogen in seedlings in a cultivar-dependent manner (Rybakova et al. 2017), further suggesting that specific seed endophytes can yield diseaseprotection effect in early development of the host.

Here, we used seed collection methods that allowed us to preserve the microbiota naturally occurring on the seed surface of four field-grown tomato types. Across four biological replicates (TT1 to TT4), endogenous seed-microbiota were found to suppress disease symptoms in juvenile seedlings of their natural hosts when challenged with a common tomato pathogen, Pseudomonas syringae pv. tomato (Fig. 1C and D). When TT4 microbiota was inoculated onto two other field tomato types, it was able to significantly reduce disease symptoms and decrease the density of Pseudomonas syringae pv. tomato by 10 - to 100 -fold (Fig. 2). Although the tomato types themselves differed in their overall susceptibility to disease, we did not observe that any single tomato type was more protected by the TT4 microbiome than another. This may suggest that the pathogen-suppressive effects of TT4, whether attributable to microbiome members with antagonistic activities against Pseudomonas syringae pv. tomato or immune system priming, are capable of acting independently of their host genotypic context. Due the manner the tomatoes were collected (which was based on plant location and fruit morphology rather than specific genotype of tomatoes), we were not able to point to the specific differences among host genotypes, but this would be useful in future studies. Furthermore, as we did not sequence the microbiome of adult plants from which seeds were collected, future work should explore if differences among seed microbiomes are driven by differences in the microbiome composition of the adult plants themselves. These microbiome differences may be a result of field location, host genotype, or other unknown factors. Our data suggest that it may be possible to breed plants to specifically recruit or harbor beneficial seed microbiomes that may ensure a more disease-resistant crop in subsequent generations.

To better understand the protective effects observed, we sequenced the bacterial communities associated with seedlings inoculated with the TT4 microbiome and found the communities to be dominated by Pantoea spp. (Fig. 3C). This is in line with community profiling results from the seed surface of Triticum and Brassica (Links et al. 2014). We then isolated culturable bacteria from seeds, and again found primarily Pantoea spp. Inoculation of seeds with our Pantoea isolates showed that they are highly protective against Pseudomonas syringae pv. tomato, both in terms of colonization and disease (Fig. 4). Pantoea spp. is a known antagonist of many bacterial (Pusey et al. 2011; Stockwell et al. 2002; Wright et al. 2001) as well as fungal (Enya et al. 2007; Links et al. 2014) pathogens, and they are common biocontrol strains. Pantoea dispersa strain ZM1 appears to be novel and not previously described as a biocontrol species, but provides protection that is on par with, if not better than, currently commercially available strains. Genome sequencing will reveal if Pantoea agglomerans strains ZM2 and ZM3 are novel biocontrol strains.

Our work also helps to disentangle the link between diversity and disease protection. Although there exists a speculative relationship between taxonomic diversity and the strength of a microbiome's disease-resistance effect, little empirical evidence exists to support or disprove this. A recent study on the protective effect of a constructed community against Pseudomonas syringae pv. tomato shows that variation in inoculum diversity affects disease-resistant effects in a significantly nonlinear manner (Berg and Koskella 2018), demonstrating that increasing taxonomic diversity can have no impact, or even decrease, the protective effect of the community. In this study, seedling bacterial communities are low in richness and diversity, dominated primarily by one genus: Pantoea, although there are multiple species and strains of Pantoea. It is possible a greater diversity of bacteria existed on the seeds, but we still find that inoculation of individual strains of Pantoea is sufficient in seedlings for protection against the pathogen used in this study. We are also aware that the fermentation step used to collect seeds might have enriched certain members of the seed microbiome that are able to survive acidic conditions. However, this may be a biologically relevant filtering step for epiphytic seed microbes, as seeds are likely to experience acidic conditions both during fermentation of fruit in the field or through the digestive track of animals.

Although we only test the protective ability of isolates against a bacterial pathogen, the Pantoea isolates and the Bacillus isolate may have other growth promoting capabilities as well, as a recent paper describes various growth promotion traits of tomato seed endophytes (in addition to disease protection) (Bergna et al. 2018). They may also have protective effects against fungal pathogens, as has been previously demonstrated in Pantoea species (Enya et al. 2007; Links et al. 2014). Practically, seed-associated bacteria are an excellent target for probiotic/biocontrol application, and it may even be possible to apply the protective strain to the flowers of the previous generous, as was demonstrated with a plant growth promoting endophyte (Mitter et al. 2017). Taken together, these studies and our results suggest that the common agricultural practice of seed sterilization may be disrupting persistent mutualisms between plants and microbes across generations. While seed sterilization is an agriculturally important procedure to purge seedtransmitted pathogens, we and other groups have shown that it may also be removing beneficial symbionts. How the simultaneous disruption of pathogenic and mutualistic symbioses would impact host health over ecological time scales, and how agricultural 
practices should preserve the beneficial traits conferred by the vertically transmitted microbiome while still preventing the spread of pathogens, are outstanding questions in need of future research.

The focus of this work was to examine the potential protective effects of seed epiphytic communities rather than describe the mechanisms underlying protection. Previous work has demonstrated that some Pantoea spp. are protective through antibiosis activity (Pusey et al. 2011; Stockwell et al. 2002), or it may also be mediated through competition for resources (Innerebner et al. 2011). In addition to direct interactions between microbes, application of Pantoea spp. to seeds ensures that germinating seedlings are in immediate contact with microbes, and this may prime the plant's immune system so that it is better able to mount a response against Pseudomonas syringae pv. tomato, thus indirectly protecting against disease. In our experiments, the data suggest that both direct and indirect mechanisms are mediating protection. We find that all strains of live bacteria, including a non-plant-associated strain of E. coli, are capable of decreasing disease severity symptoms when compared with nontreated controls. When seeds are treated with UV-killed bacteria, we find that none of the strains are capable of decreasing disease severity. Our results suggest that all bacteria included in our experiment can protect seedlings against Pseudomonas syringae pv. tomato through direct interactions, as UV-killed bacteria were unable to decrease disease severity. Additionally, we found that all live isolates except for E. coli lowered Pseudomonas syringae pv. tomato densities in seedlings, suggesting that this characteristic may be unique to our Pantoea isolates. When seedlings were treated with UV-killed bacteria, we again found that ZM1, ZM2, and ZM3 were capable of lowering Pseudomonas syringae pv. tomato densities, but E. coli was not. This suggests that some of the protective capability we are observing is conferred through indirect mechanisms, perhaps through immune activation by UV-resistant membrane-bound antigens. The inability of UV-killed E. coli to decrease Pseudomonas syringae pv. tomato density suggests that these Pantoea strains may have plant host or pathogen specific protective traits. Future work will explore protective ability of these isolates in adult plants and will further dissect direct versus indirect mechanisms of protection.

By varying the concentration of Pseudomonas syringae pv. tomato inoculated onto seedlings, we observed that increasing Pseudomonas syringae pv. tomato increases AUDPC, as expected. Interestingly, we also observed a decoupling of plant disease symptoms and pathogen density. This was similarly observed when we tested for protective effects of each isolate (Fig. 4). Here, we saw a linear increase of disease severity as Pseudomonas syringae pv. tomato inoculation was increased in inoculation density, but saw a much weaker linear correlation between dose and Pseudomonas syringae pv. tomato densities. We posit that this nonlinear increase of Pseudomonas syringae pv. tomato density might either be due to (i) a carrying capacity of Pseudomonas syringae pv. tomato density on the seedling leaves, or (ii) the possibility that the detection of dead or inactive Pseudomonas syringae pv. tomato cells disguises a linear pattern. Furthermore, disease severity was calculated based on foliar symptoms, but it is very possible Pseudomonas syringae pv. tomato asymptomatically colonizes the seedling root tissue. The entire seedlings, including roots, were homogenized prior to Pseudomonas syringae pv. tomato quantification; this may have overshadowed foliar differences in Pseudomonas syringae pv. tomato densities.

By varying the dose of the protective strain (Fig. 5), we were able to uncover that an increased dose does not necessarily correlate with decreased pathogen density, as was recently uncovered in a study investigating the protective effects of the phyllosphere community in adult tomato plants (Berg and Koskella 2018). We vary the dosage of protective Pantoea strains from less than $1 \mathrm{CFU} /$ seed to $10^{8} \mathrm{CFU} / \mathrm{seed}$, the highest of which is 5 orders of magnitude higher than the concentration at which we originally cultured bacteria off the seeds. When analyzing Pseudomonas syringae pv. tomato density after 7 days, all culturable isolates' ability to suppress growth responded in a significantly nonlinear manner to their applied density. The same is true for the two commercially available biocontrol strains. Most notably, all three TT4 isolates exhibit optimal suppression of Pseudomonas syringae pv. tomato at densities close to that found in naturally occurring seeds (40 CFU/ seed). At isolate densities above $10^{4} \mathrm{CFU} / \mathrm{seed}$, Pseudomonas syringae pv. tomato density as detected by ddPCR, reached an asymptote in all bacteria, suggesting a ceiling density beyond which additional protective strains do not yield more protection. In light of our results that UV-killed Pantoea are capable of decreasing Pseudomonas syringae pv. tomato density through presumed plantimmune activation, we posit that this activation, or priming, may be sensitive to bacterial density on the seeds. This is further supported by the result that UV-killed isolate C9-1 was the only Pantoea isolate unable to decrease Pseudomonas syringae pv. tomato density (Fig. 4D), and its dose response curve was also the only one that did not follow the cubic pattern observed in the other Pantoea isolates (Fig. 5B).

To rule out the possibility that higher densities of Pantoea were killing Pseudomonas syringae pv. tomato, which would be undistinguishable through ddPCR quantification, we treated samples with a PMAxx and repeated the ddPCR. PMA treatment blocks the amplification of dead cells and allows for measurement from only live cells. The data are qualitatively the same (data not shown), indicating that even when only live cells are quantified, Pseudomonas syringae pv. tomato densities reach an asymptote. Our results are suggestive of the possibility that plants may not only preferentially passage beneficial symbionts, (also recently shown in (Bergna et al. 2018), but it is possible that they are being passaged at an optimal density as well. This density may be driven by nutrient or physical characteristics of the seeds, or it may reflect a concentration that is most effective at inducing a host immune response in seedlings. More empirical data are needed to more robustly test these hypotheses.

Our work also demonstrates an important practical use for dose response curves. When a biocontrol agent is applied in the field, its goal may be to decrease disease severity symptoms in the host. However, in the case of foodborne human pathogens, the goal is likely to decrease total numbers of bacterial cells. The same is true for decreasing likelihood of disease transmission, or secondary effects caused by pathogens such as frost damage. We found that the optimal dose for decreasing disease severity may not be the same as that needed to decrease overall bacterial abundance. Indeed, increasing the titer of biocontrol strains may indirectly increase the number of pathogenic cells when it exceeds a biologically relevant dosage.

In conclusion, this study explores the epiphytic seed microbiome from both an ecological and applied perspective. Our fruit sterilization method is a simple yet effective modification of previous studies that allowed us to study only biologically relevant microbes on the surfaces of seeds. Through both culture-dependent and independent approaches, we described a complete microbiome, dominated by key species, which confer protection in seedlings against a common and agriculturally relevant pathogen. Furthermore, our finding that increasing the dose of a protective strain does not necessarily imply decreased pathogen load has critical importance in the field of biocontrol and probiotics. As a whole, this work highlights the importance of approaching questions from multiple perspectives, as often, these different approaches are 
likely to inform one another and increase both the validity and applicability of the results. Overall, this work not only contributes to our understanding of the ecological importance of seed-associated microbes, but it also provides novel insight as to how agricultural processes can be informed by natural patterns and used to enhance plant health and fitness.

\section{ACKNOWLEDGMENTS}

We thank A. Palkovic, R. Adamchak, and the UC Davis Student Organic Farm where tomato samples were originally collected. Specifically, we would like to acknowledge the 2016-2017 USDA SCOPE (Student Collaborative Plant breeding Education project, USDA-NIFA award number 2015-51300-24157) at UC Davis, as tomato type 4 seeds were collected from tomatoes being bred through their program. We thank V. Stockwell for providing Pantoea biocontrol strains and for helpful conversations regarding genotyping Pantoea species, and C. J. E. Metcalf for helpful discussions regarding SPLINE statistical analysis.

\section{LITERATURE CITED}

Baba, T., Ara, T., Hasegawa, M., Takai, Y., Okumura, Y., Baba, M., Datsenko, K. A., Tomita, M., Wanner, B. L., and Mori, H. 2006. Construction of Escherichia coli K-12 in-frame, single-gene knockout mutants: The Keio collection. Mol. Syst. Biol. 2:2006.0008.

Badri, D. V., Zolla, G., Bakker, M. G., Manter, D. K., and Vivanco, J. M. 2013. Potential impact of soil microbiomes on the leaf metabolome and on herbivore feeding behavior. New Phytol. 198:264-273.

Barret, M., Briand, M., Bonneau, S., Préveaux, A., Valière, S., Bouchez, O., Hunault, G., Simoneau, P., and Jacques, M.-A. 2015. Emergence shapes the structure of the seed microbiota. Appl. Environ. Microbiol. 81: 1257-1266.

Berg, M., and Koskella, B. 2018. Nutrient- and dose-dependent microbiomemediated protection against a plant pathogen. Curr. Biol. 28: 2487-2492.e3.

Bergmark, L., Pernille, H. B. P., Abu Al-Soud, W., Norman, A., Hansen, L. H., and Sørensen, S. J. 2012. Assessment of the specificity of Burkholderia and Pseudomonas QPCR assays for detection of these genera in soil using 454 pyrosequencing. FEMS Microbiol. Lett. 333:77-84.

Bergna, A., Cernava, T., Rändler, M., Grosch, R., Zachow, C., and Berg, G. 2018. Tomato seeds preferably transmit plant beneficial endophytes. Phytobiomes J. 2:183-193.

Bertani, G. 1951. Studies on lysogenesis I. J. Bacteriol. 62:293-300.

Brady, C., Cleenwerck, I., Venter, S., Vancanneyt, M., Swings, J., and Coutinho, T. 2008. Phylogeny and identification of Pantoea species associated with plants, humans and the natural environment based on multilocus sequence analysis (MLSA). Syst. Appl. Microbiol. 31:447-460.

Christian, N., Herre, E. A., Mejia, L. C., and Clay, K. 2017. Exposure to the leaf litter microbiome of healthy adults protects seedlings from pathogen damage. Proc. R. Soc. B 284:20170641.

Conrath, U. 2011. Molecular aspects of defence priming. Trends Plant Sci. 16: 524-531.

Cottyn, B., Debode, J., Regalado, E., Mew, T. W., and Swings, J. 2009. Phenotypic and genetic diversity of rice seed-associated bacteria and their role in pathogenicity and biological control. J. Appl. Microbiol. 107:885-897.

Delétoile, A., Decré, D., Courant, S., Passet, V., Audo, J., Grimont, P., Arlet, G., and Brisse, S. 2009. Phylogeny and identification of Pantoea species and typing of Pantoea agglomerans strains by multilocus gene sequencing. J. Clin. Microbiol. 47:300-310.

Dixon, P., and Palmer, M. W. 2003. VEGAN, a package of R functions for community ecology. J. Veg. Sci. 14:927-930.

Douglas, A. E. 1998. Nutritional interactions in insect-microbial symbioses: Aphids and their symbiotic bacteria Buchnera. Annu. Rev. Entomol. 43:17-37.

Edgar, R. C., Haas, B. J., Clemente, J. C., Quince, C., and Knight, R. 2011. UCHIME improves sensitivity and speed of chimera detection. Bioinformatics 27:2194-2200.

Egamberdieva, D., Wirth, S. J., Alqarawi, A. A., AbdAllah, E. F., and Hashem, A. 2017. Phytohormones and beneficial microbes: Essential components for plants to balance stress and fitness. Front. Microbiol. 8.
Enya, J., Koitabashi, M., Shinohara, H., Yoshida, S., Tsukiboshi, T., Negishi, H., Suyama, K., and Tsushima, S. 2007. Phylogenetic diversities of dominant culturable Bacillus, Pseudomonas and Pantoea species on tomato leaves and their possibility as biological control agents. J. Phytopathol. 155:446-453.

Ferreira, A., Quecine, M. C., Lacava, P. T., Oda, S., João, L. A., and Araújo, W. L. 2008. Diversity of endophytic bacteria from eucalyptus species seeds and colonization of seedlings by Pantoea agglomerans. FEMS Microbiol. Lett. 287:8-14.

Fürnkranz, M., Wanek, W., Richter, A., Abell, G., Rasche, F., and Sessitsch, A. 2008. Nitrogen fixation by phyllosphere bacteria associated with higher plants and their colonizing epiphytes of a tropical lowland rainforest of Costa Rica. ISME J. 2:561-570.

Hardoim, P. R., Hardoim, C. C. P., van Overbeek, L. S., and Dirk van Elsas, J. 2012. Dynamics of seed-borne rice endophytes on early plant growth stages. PLoS One 7:e30438.

Hassan, J. A., Zhou, Y.-M. J., and Lewis, J. D. 2017. A rapid seedling resistance assay identifies wild tomato lines that are resistant to Pseudomonas syringae pv. tomato race 1. Mol. Plant-Microbe Interact. 30:701-709.

Innerebner, G., Knief, C., and Vorholt, J. A. 2011. Protection of Arabidopsis thaliana against leaf-pathogenic Pseudomonas syringae by sphingomonas strains in a controlled model system. Appl. Environ. Microbiol. 77:3202-3210.

Johnston-Monje, D., and Raizada, M. N. 2011. Conservation and diversity of seed associated endophytes in Zea across boundaries of evolution, ethnography and ecology. PLoS One 6:e20396.

Jones, J. D. G., and Dangl, J. L. 2006. The plant immune system. Nature 444: 323-329.

Khalaf, E. M., and Raizada, M. N. 2016. Taxonomic and functional diversity of cultured seed associated microbes of the Cucurbit family. BMC Microbiol. 16:131.

Khalaf, E. M., and Raizada, M. N. 2018. Bacterial seed endophytes of domesticated cucurbits antagonize fungal and oomycete pathogens including powdery mildew. Front. Microbiol. 9:42.

King, E. O., Ward, M. K., and Raney, D. E. 1954. Two simple media for the demonstration of pyocyanin and fluorescin. J. Lab. Clin. Med. 44: 301-307.

Kozich, J. J., Westcott, S. L., Baxter, N. T., Highlander, S. K., and Patrick, D. S. 2013. Development of a dual-index sequencing strategy and curation pipeline for analyzing amplicon sequence data on the MiSeq Illumina sequencing platform. Appl. Environ. Microbiol. 79:5112-5120.

Kumar, S., Stecher, G., and Tamura, K. 2016. MEGA7: Molecular Evolutionary Genetics Analysis Version 7.0 for bigger datasets. Mol. Biol. Evol. 33: 1870-1874.

Lau, J. A., and Lennon, J. T. 2012. Rapid responses of soil microorganisms improve plant fitness in novel environments. Proc. Natl. Acad. Sci. 109: 14058-14062.

Links, M. G., Demeke, T., Gräfenhan, T., Hill, J. E., Hemmingsen, S. M., and Dumonceaux, T. J. 2014. Simultaneous profiling of seed-associated bacteria and fungi reveals antagonistic interactions between microorganisms within a shared epiphytic microbiome on Triticum and Brassica seeds. New Phytol. 202:542-553.

Lundberg, D. S., Yourstone, S., Mieczkowski, P., Jones, C. D., and Dangl, J. L. 2013. Practical innovations for high-throughput amplicon sequencing. Nat. Methods 10:999-1002.

Lymperopoulou, Despoina S., Adams, R. I., and Lindow, S. E. 2016. Contribution of vegetation to the microbial composition of nearby outdoor air. Appl. Environ. Microbiol. 82:AEM.00610-16.

Madden, L. V., Hughes, G., and van den Bosch, F. 2007. The Study of Plant Disease Epidemics. American Phytopathological Society, St. Paul, MN.

McMurdie, P. J., and Holmes, S. 2013. Phyloseq: An R package for reproducible interactive analysis and graphics of microbiome census data. PLoS One 8:e61217.

Mitter, B., Pfaffenbichler, N., Flavell, R., Compant, S., Antonielli, L., Petric, A., Berninger, T., et al. 2017. A new approach to modify plant microbiomes and traits by introducing beneficial bacteria at flowering into progeny seeds. Front. Microbiol. 8.

Morella, N. M., Yang, S. C., Hernandez, C. A., and Koskella, B. 2018. Rapid quantification of bacteriophages and their bacterial hosts in vitro and in vivo using droplet digital PCR. J. Virol. Methods 259:18-24.

Naylor, D., DeGraaf, S., Purdom, E., and Coleman-Derr, D. 2017. Drought and host selection influence bacterial community dynamics in the grass root microbiome. ISME J. 11:2691-2704.

Newman, M.-A., Dow, J. M., Molinaro, A., and Parrilli, M. 2007. Priming, induction and modulation of plant defense responses by bacterial lipopolysaccharides. J. Endotoxin Res. 13:69-84. 
Pusey, P. L., Stockwell, V. O., Reardon, C. L., Smits, T. H. M., and Duffy, B. 2011. Antibiosis activity of Pantoea agglomerans biocontrol strain e 325 against Erwinia amylovora on apple flower stigmas. Phytopathology 101: 1234-1241.

Quast, C., Pruesse, E., Yilmaz, P., Gerken, J., Schweer, T., Yarza, P., Peplies, J., and Glöckner, F. O. 2013. The SILVA ribosomal RNA gene database project: Improved data processing and web-based tools. Nucleic Acids Res. 41:D590-D596

Rajendran, D. K., Park, E., Nagendran, R., Hung, N. B., Cho, B.-K., Kim, K.-H., and Lee, Y. H. 2016. Visual analysis for detection and quantification of Pseudomonas cichorii disease severity in tomato plants. Plant Pathol. J. 32:300-310.

Rezki, S., Campion, C., Simoneau, P., Jacques, M.-A., Shade, A., and Barret, M. 2018. Assembly of seed-associated microbial communities within and across successive plant generations. Plant Soil 422:67-79.

Rezzonico, F., Smits, T. H. M., Montesinos, E., Frey, J. E., and Duffy, B. 2009. Genotypic comparison of Pantoea agglomerans plant and clinical strains. BMC Microbiol. 9:204.

Ritpitakphong, U., Falquet, L., Vimoltust, A., Berger, A., Métraux, J.-P., and L'Haridon, F. 2016. The microbiome of the leaf surface of Arabidopsis protects against a fungal pathogen. New Phytol. 210:1033-1043.

Rognes, T., Flouri, T., Ben Nichols, C. Q., and Mahé, F. 2016. VSEARCH: A versatile open source tool for metagenomics. PeerJ Preprints 4:e2409v1.

Rybakova, D., Mancinelli, R., Wikström, M., Birch-Jensen, A.-S., Postma, J., Ehlers, R.-U., Goertz, S., and Berg, G. 2017. The structure of the Brassica napus seed microbiome is cultivar-dependent and affects the interactions of symbionts and pathogens. Microbiome 5:104.

Santhanam, R., Luu, V. T., Weinhold, A., Goldberg, J., Oh, Y., and Baldwin, I. T. 2015. Native root-associated bacteria rescue a plant from a sudden-wilt disease that emerged during continuous cropping. Proc. Natl. Acad. Sci. 112:E5013-E5020.

Schloss, P. D., Westcott, S. L., Ryabin, T., Hall, J. R., Hartmann, M., Hollister, E. B., Lesniewski, R. A., et al. 2009. Introducing Mothur: Open-source, platform-independent, community-supported software for describing and comparing microbial communities. Appl. Environ. Microbiol. 75: 7537-7541.

Shade, A., Jacques, M.-A., and Barret, M. 2017. Ecological patterns of seed microbiome diversity, transmission, and assembly. Curr. Opin. Microbiol. 37:15-22.

Song, G. C., Choi, H. K., Kim, Y. S., Choi, J. S., and Ryu, C.-M. 2017. Seed defense biopriming with bacterial cyclodipeptides triggers immunity in cucumber and pepper. Sci. Rep. 7:14209.
Stockwell, V. O., Johnson, K. B., Sugar, D., and Loper, J. E. 2002. Antibiosis contributes to biological control of fire blight by Pantoea agglomerans strain Eh252 in orchards. Phytopathology 92:1202-1209.

Takahashi, S., Tomita, J., Nishioka, K., Hisada, T., and Nishijima, M. 2014. Development of a prokaryotic universal primer for simultaneous analysis of bacteria and Archaea using next-generation sequencing. PLoS One 9: e105592.

Tamura, K., and Nei, M. 1993. Estimation of the number of nucleotide substitutions in the control region of mitochondrial DNA in humans and chimpanzees. Mol. Biol. Evol. 10:512-526.

Truyens, S., Weyens, N., Cuypers, A., and Vangronsveld, J. 2015. Bacterial seed endophytes: Genera, vertical transmission and interaction with plants. Environ. Microbiol. Rep. 7:40-50.

Vannier, N., Mony, C., Bittebiere, A.-K., Michon-Coudouel, S., Biget, M., and Vandenkoornhuyse, P. 2018. A microorganisms' journey between plant generations. Microbiome 6:79.

Wagner, M. R., Lundberg, D. S., Coleman-Derr, D., Tringe, S. G., Dangl, J. L., and Mitchell-Olds, T. 2014. Natural soil microbes alter flowering phenology and the intensity of selection on flowering time in a wild Arabidopsis relative. Ecol. Lett. 17:717-726.

Walterson, A. M., and Stavrinides, J. 2015. Pantoea: Insights into a highly versatile and diverse genus within the Enterobacteriaceae. FEMS Microbiol. Rev. 39:968-984.

Weisburg, W. G., Barns, S. M., Pelletie, D. A., and Lane, D. J. 1991. 16S ribosomal DNA amplification for phylogenetic study. J. Bacteriol. 173: 697-703.

Wickham, H. 2009. Ggplot2: Elegant Graphics for Data Analysis. Use R! Springer, New York.

Wright, S. A. I., Zumoff, C. H., Schneider, L., and Beer, S. V. 2001. Pantoea agglomerans strain EH318 produces two antibiotics that inhibit Erwinia amylovora in vitro. Appl. Environ. Microbiol. 67:284-292.

Zahran, H. H. 1999. Rhizobium-legume symbiosis and nitrogen fixation under severe conditions and in an arid climate. Microbiol. Mol. Biol. Rev. 63: 968-989

Zamioudis, C., Korteland, J., Van Pelt, J. A., van Hamersveld, M., Dombrowski, N., Bai, Y., Hanson, J., et al. 2015. Rhizobacterial volatiles and photosynthesis-related signals coordinate MYB72 expression in Arabidopsis roots during onset of induced systemic resistance and iron-deficiency responses. Plant J. 84:309-322. 